\title{
RESEARCH
}

\section{An Expanded CAG Repeat Sequence in Spinocerebellar Ataxia Type 7}

\author{
Kerstin Lindblad, ${ }^{1,10}$ Marja-Liisa Savontaus, ${ }^{2}$ Giovanni Stevanin, ${ }^{4}$ \\ Monica Holmberg, ${ }^{5}$ Kathleen Digre, ${ }^{6}$ Cecilia Zander, ${ }^{1}$ Henrik Ehrsson, ${ }^{1}$ \\ Gilles David, ${ }^{4}$ Ali Benomar, ${ }^{8}$ Eeva Nikoskelainen, ${ }^{3}$ Yvon Trottier, ${ }^{9}$ \\ Gösta Holmgren, ${ }^{5}$ Louis J. Ptacek, ${ }^{6,7}$ Anu Anttinen, ${ }^{3}$ Alexis Brice, ${ }^{4}$ and \\ Martin Schalling ${ }^{1}$
}

\begin{abstract}
${ }^{1}$ Neurogenetics Unit, Department of Molecular Medicine, Karolinska Hospital, Stockholm, Sweden; ${ }^{2}$ Department of Medical Genetics and ${ }^{3}$ Department of Neurology, University of Turku, Turku, Finland; ${ }^{4}$ INSERM U289 and Federation de Neurologie, Hôpital de Salpêtrière, Paris, France; ${ }^{5}$ Department of Clinical Genetics, University Hospital, Umeå, Sweden; ${ }^{6}$ Department of Neurology and ${ }^{7}$ Department of Human Genetics, University of Utah, Salt Lake City, Utah $84112 ;{ }^{8}$ Service de Neurologie, Hôpital des Spécialitès, Rabat, Morocco; ${ }^{9}$ Institut de Génètique et de Biologie Moléculaire et Cellulaire, Centre National de la Recherche Scientifique, Illkirch, France
\end{abstract}

Expanded CAG repeat sequences have been identified in the coding region of genes mutated in several neurodegenerative disorders, including spinocerebellar ataxia type 1 and Machado-Joseph disease. In all disorders described to date the CAG expansion codes for an elongated polyglutamine chain. An increased polyglutamine chain size leads to a more severe disease, thus correlating with the genetic anticipation seen in repeat expansion disorders. Spinocerebellar ataxia type 7 (SCA7) is an autosomal dominant spinocerebellar ataxia with anticipation and a progressive degeneration of the cerebellar cortex. Using repeat expansion detection (RED), a method in which a thermostable ligase is used to detect repeat expansions directly from genomic DNA, we have analyzed 8 SCA7 families for the presence of CAG repeat expansions. RED products of $150-240 \mathrm{bp}$ were found in all affected individuals and found to cosegregate with the disease $(P<0.000001, n=66)$, indicating strongly that a CAG expansion is the cause of SCA7. On the basis of a previously established correlation between RED product sizes and actual repeat sizes in Machado-joseph disease, we were able to estimate the average expansion size in SCA7 to be 64 CAG copies.

Spinocerebellar ataxia type 7 (SCA7) belongs to a group of autosomal dominant cerebellar ataxias (ADCA) where degeneration of pathways associated with the cerebellum lead to ataxia, dysarthria, dysmetria, and intention tremor (Harding 1993; Rosenberg 1995). The clinical signs within this large group of disorders overlap greatly, making distinction between the different subtypes difficult. Characterization is further complicated by variation of clinical signs within families. Although all patients show progressive ataxia, the associated signs, age of onset, and clinical course are highly variable. During the past few years sev-

${ }^{10}$ Corresponding author.

E-MAIL keli@gen.ks.se; FAX 468327734. eral genetic loci have been mapped to different chromosomes, thereby separating various spinocerebellar ataxias (SCAs).

The clinical signs of SCA7 include macular degeneration leading to blindness, in addition to the more common cerebellar signs (Anttinen et al. 1986; Benomar et al. 1994; Gouw et al. 1994). SCA7 maps to chromosome 3p14-21.1 and is characterized by genetic anticipation including both a younger age of onset and a more severe phenotype in successive generations of a given family (Benomar et al. 1995; Gouw et al. 1995; Holmgren et al. 1995). In Machado-Joseph disease (MJD/SCA3; Kawaguchi et al. 1994) and spinocerebellar ataxia type 1 (SCA1; Orr et al. 1993) anticipation correlates with expanded CAG re- 


\section{LINDBLAD ET AL.}

peats within the coding region of the respective genes. These repeats encode a polyglutamine tract that when expanded, confers a gain of function in a not yet established way (for review, see Lindblad and Schalling 1996). Glutamine is encoded by either a CAG or a CAA triplet, both of which are found in polymorphic repeats in human genes. Therefore, a search for CAG or CAA expansions would be motivated in neurological disorders displaying anticipation.

To perform genetic screening for such sequences, we have developed the repeat expansion detection (RED) method, in which a thermostable ligase is used to detect repeat expansions directly from genomic DNA (Schalling et al. 1993; Lindblad et al. 1994). Here we have used the RED method to analyze 67 individuals from eight families for CAG repeat expansions. RED products of $150-240 \mathrm{bp}$ were found in all affected individuals, indicating a CAG expansion as the cause of SCA7.

\section{RESULTS AND DISCUSSION}

\section{Methodological Considerations}

We analyzed all individuals with the RED method (Schalling et al. 1993, 1996; Lindblad et al. 1994) using a (CTG) ${ }_{10}$ oligonucleotide, giving RED products at an interval of 30 bases (Fig. 1). The protocol was modified from the original method (Schalling et al. 1993) in several ways. The 30-base oligonucleotide used here provides improved size resolution compared to the previously used 51-base oligonucleotide. In humans, the 30-base oligonucleotide results in a RED product of 120 bases ( 40 repeat copies) in almost all individuals tested. Therefore, 40 copies represent the lower level for detection of expansions with the current protocol. This lower level of detection was suitable for the present study but is not absolute, as modifications of the size of the repeat oligonucleotide can alter the lower limit. The oligonucleotide was 5'-phosphorylated during synthesis, thereby lowering reaction failure rate. The transfer of DNA from gel to membrane was facilitated and made more uniform by a semidry capillary blotting procedure. Details of these improvements are found in the Methods section.

Potentially, any disease-related expansion larger than 40 copies should be identifiable using RED, provided that families are large enough to permit cosegregation analysis and, thereby, ex-

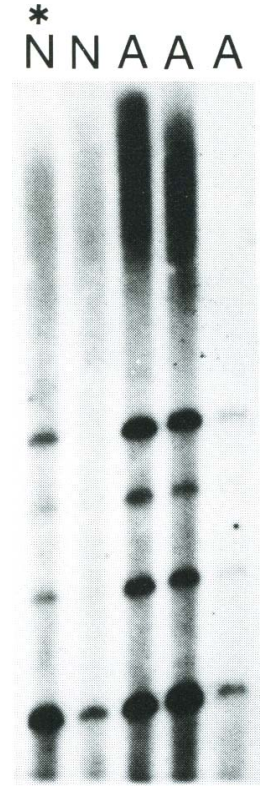

Figure 1 Autoradiograph of RED products from part of an SCA7 family using a (CTG) 10 oligonucleotide. The lowest band in each lane represents 90 bases and each additional band represents an additional 30 bases. (A) Affected individuals; $(N)$ individuals not affected to date; $\left(\mathrm{N}^{\star}\right)$ an unaffected individual who is identical to individual III:7 in Fig. 2. This individual carries an expansion, but lacks the entire disease haplotype, suggesting that the expansion is unrelated to disease.

clusion of repeats unrelated to disease. Owing to the variation in expansion frequency among different ethnic groups (G. Sirugo, pers. comm.), the problems arising from unrelated expansions can be more or less severe. The problem with unrelated repeats can be reduced by the ability to identify two differently sized repeat expansions in the same individual. This is achieved through analysis of the intensity of the RED bands within one lane (Lindblad et al. 1996). Thus, the segregation of several unrelated repeats can be followed within one family.

\section{Cosegregation between Expanded RED Products and Phenotype}

All affected individuals showed RED products of $150,180,210$, or $240 \mathrm{bp}$ (Table 1). To test the hypothesis that a CAG expansion cosegregated with the disease, we assigned all RED products of $150-240 \mathrm{bp}$ as the disease allele. Using $\chi^{2}$ analysis, a significant cosegregation between disease allele and phenotype was observed $(P<0.000001$, 


\begin{tabular}{|llll|}
\hline Table 1. RED Product Distribution in SCA7 and MJD/SCA3 \\
\hline \multicolumn{3}{c|}{ Number of expanded alleles } \\
\cline { 2 - 4 } $\begin{array}{lll}\text { RED product size } \\
\text { (bp) }\end{array}$ & $\begin{array}{l}\text { unaffected SCA7 } \\
\text { spouses }(n=14)\end{array}$ & $\begin{array}{l}\text { SCA7 patients } \\
(n=31)\end{array}$ & $\begin{array}{l}\text { MJD/SCA3 patients } \\
(n=44)\end{array}$ \\
\hline 150 & & 3 & \\
180 & $2^{\mathrm{a}}$ & 16 & 2 \\
210 & $1^{\mathrm{a}}$ & 11 & 37 \\
240 & & 1 & 4 \\
270 & $2^{\mathrm{a}}$ & $4^{\mathrm{a}}$ & $5^{\mathrm{a}}$ \\
$\geqslant 300$ & \multicolumn{3}{|}{} \\
\hline
\end{tabular}

$n=66$ ), strongly suggesting that a CAG expansion is involved in SCA7. In five cases we observed repeat instability expressed as an increase in RED product size in affected offspring.

\section{RED Products in Healthy Spouses}

Four of 14 (29\%) healthy spouses showed expansions $\geqslant 150$ bp in size (Table 1 ). This is in agreement with previous findings, where $\sim 30 \%$ of the normal population show expansions of $\geqslant 180 \mathrm{bp}$ (Schalling et al. 1993; Lindblad et al. 1995). Two of these expansions were $>240 \mathrm{bp}$, making possible a separate segregation analysis that indicated these longer alleles were unrelated to disease. An example of this can be found in Figure 2, where an expansion of $330 \mathrm{bp}$ originates from the unaffected parent (II:2) and is inherited by two unaffected (III:3 and III:4) and one affected (III:5) offspring (Fig. 2).

\section{RED Products in Unaffected Offspring}

Thirteen of 22 unaffected offspring showed expansions of $\geqslant 150 \mathrm{bp}$. We studied the segregation of repeats and performed haplotype analysis in this group. Two (III:4 in Fig. 2 and not shown) of the 13 individuals had the entire affected haplotype and a repeat in the pathologic range. One additional individual (III:3 in Fig. 2) had a repeat expansion in the pathologic range, but only part of the affected haplotype. This expansion was inherited from the affected parent (II:1 in Fig. 2). Both III: 3 and III:4 are the same age as or younger than other family members (III:1, III:5, and III:8 in Fig. 2), who have developed symptoms only recently, leaving III:3 and III:4 at risk of developing disease. Alternatively, it is possible that an affected parent carries two different 180-bp expansions, one that is related to disease and one that is not.

The other 10 unaffected offspring showing expansions lacked the affected haplotype. One individual (III:2 in Fig. 2) failed repeatedly on RED, but had the affected haplotype, making him/her an additional individual at risk.

In our experience there is no upper size limit above which repeats are always pathological or always without a phenotype. Linking an expanded repeat to disease is, therefore, dependent on cosegregation within a given family and is best achieved by establishing a size range that covers all disease alleles. Alternatively, if the aim is to use RED as a diagnostic tool for a cloned expansion, a second oligonucleotide can be incorporated in the reaction. This oligonucleotide should be slightly different in size to the repeat oligonucleotide and complementary to the sequence flanking the repeat. Therefore, locusspecific doublet bands are generated on the gel if the expansion is at the locus tested for.

\section{Disease Gene Localization}

Tight linkage to chromosome 3p14-21.1 was observed in all families studied, confirming that they are a homogenous group. Two recombinations in a previously unlinked family (II:5 in Fig. 2 and not shown) place the disease locus centromeric to marker D3S1300, which is in agreement with previous observations (Benomar et al. 1995). The recombination in individual III:3 (Fig 2) would place the disease locus telomeric to 


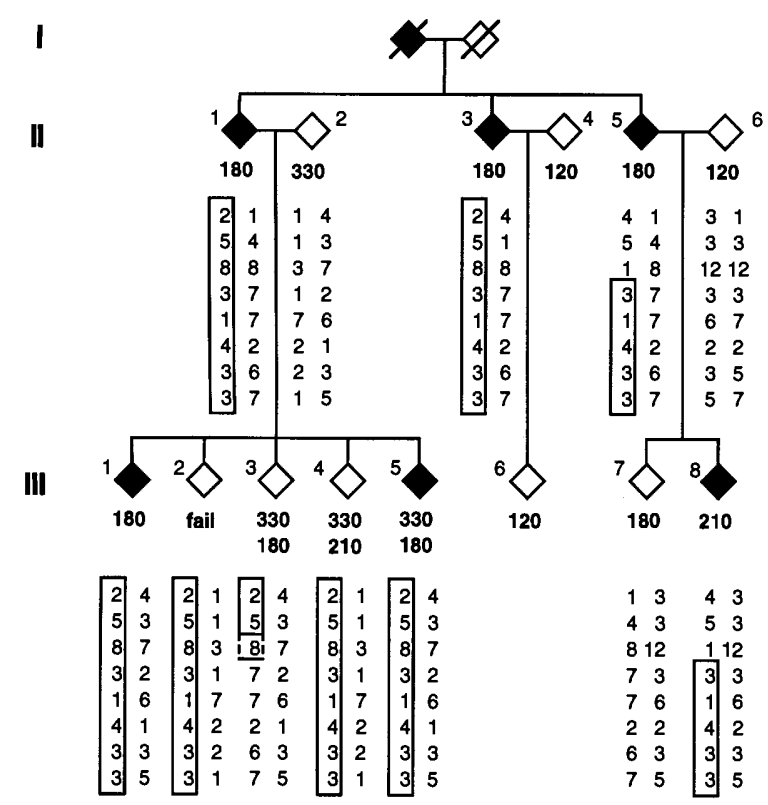

Figure 2 Pedigree showing part of an SCA7 family. Bold numbers denote RED product sizes. Below haplotypes constructed from marker D3S3553, D3S3722, D3S1300, D3S1312, D3S1600, D3S1287, D3S1285, and D3S1296 are shown. Individuals with two RED product sizes were scored as carrying two separate expansions, on the basis of analysis of the intensity of the differently sized bands within one lane (see Lindblad et al. 1996). Affected individuals show a 180-bp repeat except for III:8, where an expansion to $210 \mathrm{bp}$ occurred, corresponding to a shift in age at onset from 22 years to 14 years of age. All individuals in generation III are young and the ones affected developed symptoms only recently. Note that the unaffected individuals III:3, III:4, and III:7 show RED products of the same size as the affected individuals. Individual III:4 carries the disease allele haplotype and is at risk of developing the disease. Individual III:7 lacks the affected haplotype. Therefore, the affected parent probably carries two 180-bp expansions and transmitted the one unrelated to disease to III:7. Individual III:3 carries only part of the affected haplotype. If the expansion is related to disease, subsequently the disease locus would be placed between markers D3S1300 and D3S1312. It remains possible that the repeat observed is unrelated to disease, in analogy with individual III:7. Individual III:2 failed repeatedly to give a detectable RED product and was excluded from the cosegregation analysis. This individual shows an affected haplotype and is at risk of developing the disease. Individuals have been scrambled and marked as unisex to prevent identification.

D3S1312 if the 180-bp expansion is diseaserelated. If so, the gene would reside in the $1.8-\mathrm{cM}$ region between markers D3S1300 and D3S1312, narrowing the candidate region from previous reports (Benomar et al. 1995; Gouw et al. 1995; Holmgren et al. 1995). It remains possible that two 180-bp repeats from different genomic loci segregated from individual II:1, only one of which is disease-specific. In the event that individual III:3 displays an unrelated repeat of the same size, no centromeric delineation would be possible in our study.

\section{Estimate of Pathological Repeat Size}

To determine the actual repeat copy number in SCA7 patients, we used a previously established correlation between RED product size and the actual repeat copy number in MJD/SCA3 (Table 1) (Lindblad et al. 1996). In MJD/SCA3, RED product sizes correlate well with the actual repeat copy number as determined by PCR (Lindblad et al. 1996), with almost identical average sizes seen by RED and PCR. Assuming that a similar correlation exist also in SCA7, the actual repeat size average would be -193 bp (64 repeat copies) in the SCA7 families analyzed here. This is somewhat shorter than what is found in MJD/SCA3 (Maciel et al. 1995; Dürr et al. 1996; Lindblad et al. 1996), but longer than in SCA1 (Orr et al. 1993).

One individual affected already at 16 months showed two alleles of 210 and $420 \mathrm{bp}$, respectively (Table 1). We did not observe any allele above $180 \mathrm{bp}$ in the parents: possibly the repeat expanded to 210 as well as $420 \mathrm{bp}$, indicating that this individual is a somatic mosaic with sizes ranging from 210 to $420 \mathrm{bp}$ at the single-cell level. A similar somatic mosaicism with up to 450 bp of CAG sequence has been reported in Huntington's disease (Telenius et al. 1994).

\section{Possibilities for Gene Isolation}

Because an antipolyglutamine antibody has detected protein products in lymphocytes from SCA7 patients (Trottier et al 1995), it is likely that the CAG repeat detected with RED is expressed. Therefore, the DNA sequence flanking the repeat is most likely part of the coding region of the gene and could be used for gene isolation from cDNA libraries. If the repeat expansion was isolated, a flanking sequence could be obtained. Here, RED constitutes a powerful tool as it can detect the repeat in any type of genetic material. Repeat isolation could be accomplished either by 


\section{CAG REPEAT EXPANSION IN SCA7}

screening of clones from patient derived genomic libraries or by the successive reduction in genomic complexity by DNA fractionation techniques and RED analysis of the resulting pools.

\section{Future RED Potential}

In the present study the chromosomal location of the disease was known before our RED analysis, making it convenient to construct haplotypes that increase the power of the repeat analysis. However, this is not needed for repeat identification using the RED method. The fact that the method screens for the actual mutation eliminates chromosomal crossovers and reduces the need for large informative families. Establishing a disease allele size range in a particular disorder further helps in eliminating unrelated repeats and usually decreases the rate of false positives to a degree where a single unlinked family of moderate size can be sufficient to generate a statistically significant correlation between a disease and repeat expansion (Lindblad et al. 1996). Once a disease-associated trinucleotide repeat expansion has been found, the focus of gene cloning efforts can be limited to trinucleotide repeat containing genes.

\section{Summary}

Cosegregation between a CAG expansion and SCA7 was established using RED. All affected individuals show an expanded CAG repeat that is in the size range found in SCA1 and MJD/SCA3. We conclude that a CAG expansion is very likely to be involved in the disease mechanism of SCA7. We calculated an average size of $64 \mathrm{CAG} / \mathrm{CTG}$ copies in the eight families analyzed in this study.

\section{METHODS}

\section{Families}

Affected and unaffected individuals from eight families with SCA7 were analyzed, including three Moroccan (Benomar et al. 1994), two French (Benomar et al. 1994), one Finnish (Anttinen et al. 1986), one Swedish (Holmgren et al. 1995), and one American family (Gouw et al. 1994) (in total 31 affected and 36 unaffected individuals, 14 of which were spouses). All families had been characterized previously as SCA7 and linked to chromosome 3p (Benomar et al. 1994; Gouw et al. 1995; Holmgren et al. 1995; data not shown).

\section{Sources of Genomic DNA}

Human genomic DNA was prepared from blood samples using a standard phenol/chloroform extraction procedure
(Sambrook et al. 1989). Alternatively, blood lymphocytes were lysed by adding 1.5 volumes of a solution containing $0.32 \mathrm{~m}$ sucrose, $10 \mathrm{~mm}$ Tris ( $\mathrm{pH} 7.6$ ), $5 \mathrm{~mm}$ EDTA, and 5\% Triton X-100. Nuclei were collected at $3500 \mathrm{rpm}$ for 10 min, vortexed thoroughly, and washed and pelleted twice at $3000 \mathrm{rpm}$ in the above solution without Triton. DNA was extracted from nuclei using the Qiagen kit (Qiagen Inc., Chatsworth, CA) according to the protocol supplied by the manufacturer.

\section{RED Analysis}

All reactions were performed on a GeneAmp PCR System 9600 (Perkin Elmer Cetus, Norwalk, CT), using the following conditions: Reactions $(10 \mu \mathrm{l})$ containing $1 \mu \mathrm{g}$ of genomic DNA, $50 \mathrm{ng}$ of 5 '-end phosphorylated (CTG) ${ }_{10}$ oligonucleotide (Pharmacia Biotech, Uppsala, Sweden), and 10 units of Ampligase (Epicentre Technologies, Madison, WI) with the supplied Ampligase buffer were incubated at $94^{\circ} \mathrm{C}$ for $5 \mathrm{~min}$. Thereafter, samples were taken through 495 cycles of $80^{\circ} \mathrm{C}$ for $30 \mathrm{sec}$ and $94^{\circ} \mathrm{C}$ for $10 \mathrm{sec}$ (Schalling et al. 1993). Samples diluted in $\mathrm{H}_{2} \mathrm{O}$ were buffered to $\mathrm{pH}$ 8.0 by the addition of $1 / 10$ volume of $10 \mathrm{~mm}$ Tris, and 0.1 mM EDTA to the RED reaction.

Samples were heat denatured in $50 \%$ formamide for 5 min before electrophoresis on a $6 \%$ denaturing polyacrylamide/ $6 \mathrm{~m}$ urea gel. The DNA was subjected subsequently to capillary blotting by placing a wet Hybond $\mathrm{N}^{+}$membrane on top of the gel, followed by three dry $3 \mathrm{MM}$ Whatman papers, a glass plate, and a weight. The transfer was left for $2 \mathrm{hr}$. After UV immobilization, membranes were hybridized in Rapid Hybe buffer (Amersham, Little Chalfont, UK) for $1 \mathrm{hr}$ at $60^{\circ} \mathrm{C}$ to a $(\mathrm{CAG})_{10}$ oligonucleotide that had been 3 '-end labeled (Schalling et al. 1990) using terminal deoxynucleotidyl transferase (Amersham) and $\left[{ }^{32} \mathrm{P}\right]$ dATP (NEG 012Z, NEN Du Medical, Wilmington, DE) to a specific activity of $2 \times 10^{9}$ to $9 \times 10^{9} \mathrm{cpm} / \mu \mathrm{g}$. Membranes were washed in $1 \times \mathrm{SSC}, 0.1 \%$ SDS for $0.5 \mathrm{hr}$ at $60^{\circ} \mathrm{C}$, and autoradiographed 1-3 days on NEN X-ray film using an intensifying screen.

A band of 90 bases [three ligated (CTG) ${ }_{10}$ oligonucleotides] was used as a positive control for the RED assay. Only samples displaying this band were used for the calculations presented in this paper. This product most likely represents ligations at multiple short repeat loci in the genome (Stalling 1994; Gastier et al. 1996) and therefore should be present in every individual. Families segregating two CAG expansions of different sizes were analyzed both with respect to the highest molecular mass band and to subsets of bands with increased intensity within each lane (Lindblad et al. 1996).

\section{Statistical Analysis}

RED products of $150-240 \mathrm{bp}$ were defined as the disease allele. The probability of cosegregation between the phenotype and the disease allele was calculated using $\chi^{2}$ analysis using a $2 \times 2$ contingency table with classifications of "disease allele" or "not disease allele" and "affected" or "unaffected."

\section{ACKNOWLEDGMENTS}

We are indebted to the family members for their invalu- 


\section{LINDBLAD ET AL.}

able participation. We thank Cecilia Engmér for technical support and Yves Lutz for producing the $1 \mathrm{C} 2 \mathrm{mAb}$. This study was funded by the EC Biomed 1 (grant Gene CT930060), Swedish Medical Reseach Council (grants B9413XA-10995-02B, B95-13XB-10909-02B, and B95-19C9745-05B), Svenska Läkarsällskapet, Thuring stiftelse, Söderström-Königska stiftelse, funds from the Karolinska Institute and Karolinska Hospital, National Institutes of Health grant NS32711 (to L.P.) and funds from the Association Française Centre les Myopathies and the VERUM Foundation (to A.B.). Martin Schalling is the recipient of the Ireland Award and a National Alliance for Research on Schizophrenia and Affective Disorder Established Investigator Award.

The publication costs of this article were defrayed in part by payment of page charges. This article must therefore be hereby marked "advertisement" in accordance with 18 USC section 1734 solely to indicate this fact.

\section{REFERENCES}

Anttinen, A., E. Nikoskelainen, R.J. Martilla, R. Grenman, B. Falck, E. Aarnisalo, and H. Kalimo. 1986. Familial olivopontocerebellar atrophy with macular degeneration: A separate entity among the olivopontocerebellar atrophies. Acta Neurol. Scand. 73: $180-190$.

Benomar, A., E. Le Guern, A. Dürr, H. Ouhabi, G. Stevanin, M. Yahyaoui, T. Chkili, Y. Agid, and A. Brice. 1994. Autosomal-dominant cerebellar ataxia with retinal degeneration (ADCA type II) is genetically different from ADCA type I. Anal. Neurol. 35: 439-444.

Benomar, A., L. Krols, G. Stevanin, G. Cancel, G. David, H. Ouhabi, J.-J. Martin, A. Dürr, A. Zaim, N. Ravisé, C. Busque, C. Penet, N. Van Regemorter, J. Weissenbach, M. Yahyaoui, T. Chkili, Y. Agid, C. Van Broeckhoven, and A. Brice. 1995. The gene for autosomal dominant cerebellar ataxia with pigmentary macular dystrophy maps to chromosome 3p12-p21.1. Nature Genet. 10: $84-88$.

Dürr, A., G. Stevanin, G. Cancel, C. Duyckaetts, N. Abbas, O. Didierjean, H. Chneiweiss, A. Benomar, O. Lyon-Caen, J. Julien, M. Serdaru, C. Penet, Y. Agid, and A. Brice. 1996. Spinocerebellar ataxia type 3 and Machado-Joseph disease: Clinical, molecular and neuropathological features. Anal. Neurol. 39: 122-131.

Gastier, J.M., T. Brody, J.C. Pulido, T. Businga, S. Sunden, X. Hu, S. Maitra, K.H. Buetow, J.C. Murray, V.C. Sheffield, M. Boguski, G.M. Duyk, and T.J. Hudson. 1996. Development of a screening set for new (CAG/CTG)n dynamic mutations. Genomics 32: 75-85.

Gouw, L.G., K.B. Digre, C.P. Harris, J.H. Haines, and L.J. Ptacek. 1994. Autosomal-dominant cerebellar ataxia with retinal degeneration: Clinical, neuropathologic, and genetic analysis of a large kindred. Neurology 44: $1441-1447$.

Gouw, L.G., C.D. Kaplan, J.H. Haines, K.B. Digre, S.L. Rutledge, A. Matilla, M. Leppert, H.Y. Zoghbi, and L.J.
Ptacek. 1995. Retinal degeneration characterizes a spinocerebellar ataxia mapping to chromosome $3 \mathrm{p}$. Nature Genet. 10: 89-93.

Harding, A.E. 1993 Clincal features and classification of the late onset autosomal dominant cerebellar ataxias. In Advances in neurology, Vol 61: Inherited ataxias (ed. A.E. Harding, and P. Deufel), pp. 1-14. Raven Press, New York, NY.

Holmberg M., J. Johansson, L. Forsgren, J. Heijbel, O. Sandgren, and G. Holmgren. 1995. Localization of autosomal dominant cerebellar ataxia associated with retinal degeneration and anticipation to chromosome 3p12-p21.1. Hum. Mol. Genet. 4: 1441-1445.

Kawaguchi, Y., T. Okamoto, M. Taniwaki, M. Aizawa, M. Inoue, S. Katayama, H. Kawakami, S. Nakamura, M. Nishimura, I. Akiguchi, S. Narumiya, and A. Kakizuka. 1994. CAG expansions in a novel gene for Machado-Joseph disease at chromosome 14q32.1. Nature Genet. 8: 221-228.

Lindblad, K. and M. Schalling. 1996. Clinical implications of unstable DNA sequences. ACTA Paediatr. 85: 265-271.

Lindblad, K., C. Zander, M. Schalling, and T. Hudson. 1994. Growing triplet repeats. Nature Genet. 7: 124.

Lindblad, K., P-O. Nylander, A. De bryun, D. Sourey, C. Zander, C. Engström, G. Holmgren, T. Hudson, J. Chotai, J. Mendlewicz, C. Van Broeckhoven, M. Schalling, and R. Adolfsson. 1995. Detection of expanded CAG repeats in bipolar affective disorder using the repeat expansion detection (RED) method. Neurobiol. Dis. 2: 55-62.

Lindblad, K., A. Lunkes, P. Maciel, G. Stevanin, C. Zander, T. Klockgether, T. Ratzlaff, A. Brice, G. A. Rouleau, T. Hudson, G. Auburger, and M. Schalling. 1996. Mutation detection in Machado-Joseph disease using Repeat Expansion Detection. Mol. Med. 2: 77-85.

Maciel, P., C. Gaspar, A.L. DeStefano, I. Silveira, P. Cutinho, J. Radvany, D.M. Dawson, L. Sudarsky, J. Guimaraes, J.E. Loureiro, M.M. Nezarati, L.I. Corwin, I. Lopes-Cendes, K. Rooke, R. Rosenberg, P. MacLeod, L.A. Farrer, J. Sequeiros, and G.A. Rouleau. 1995. Correlation between CAG repeat length and clinical features in Machado-Joseph disease. Am. J. Hum. Genet. 57: 54-61.

Orr, H.T., M. Chung, S. Banfi, T.J. Kwiatkowski Jr., A. Servadio, A.L. Beaudet, A.E. McCall, L.A. Duvick, L.P.W. Ranum, and H.Y. Zoghbi. 1993. Expansion of an unstable trinucleotide (CAG) repeat in spinocerebellar ataxia type 1. Nature Genet. 4: 221-226.

Rosenberg, R.N. 1995 Autosomal dominant cerebellar phenotypes: The genotype has settled the issue. Neurology 45: 1-5.

Sambrook, J., E.F. Fritsch, and T. Maniatis. 1989. 


\section{CAG REPEAT EXPANSION IN SCA7}

Molecular cloning: A laboratory manual, 2nd ed. Cold

Spring Harbor Laboratory Press, Cold Spring Harbor, NY.

Schalling, M., K. Friberg, K. Seroogy, P. Riederer, E. Bird, S. Schiffman, P. Mailleux, J-J. Vanderhaeghen, S. Kuga, M. Goldstein, K. Kitahama, P.H. Luppi, M. Jouvet, and T. Hökfeldt. 1990. Analysis of expression of cholecystokinin in dopamine cells in the ventral mesencephalon of several species and in humans with schizophrenia. Proc. Natl. Acad. Sci. 87: 8427-8431.

Schalling, M., T.J. Hudson, K.H. Buetow, and D.E. Housman. 1993. Direct detection of novel expanded trinucleotide repeats in the human genome. Nature Genet. 4: 135-139.

Schalling, M., C. Erickson-Burgess, C. Zander, K. Lindblad, J. Johansen, and T. Hudson. 1996.

RED-Repeat expansion detection. In Laboratory protocols for mutation detection (ed. U. Landegren), pp. 174-179. Oxford University Press, New York, NY.

Stalling, R.L. 1994. Distribution of trinucleotide microsatellites in different categories of mamalian genomic sequences: Implications for human genetic diseases. Genomics 21: 116-121.

Telenius, H., B. Kremer, Y.P. Goldberg, J. Theilmann, S.E. Andrew, J. Zeisler, S. Adam, C. Greenberg, E.J. Ives, L.A. Clarke, and M.R. Hayden. 1994. Somatic and gonadal mosaicism of the Huntington disease gene CAG repeat in brain and sperm. Nature Genet. 6: 409-414.

Trottier, Y., Y. Lutz, G. Stevanin, G. Imbert, D. Devys, G. Cancel, F. Saudou, C. Weber, G. David, L. Tora, Y. Agid, A. Brice, and J.-L. Mandel. 1995. Polyglutamine expansion as a pathological epitope in Huntington's disease and four dominant cerebellar ataxias. Nature 378: 403-405.

Received June 20, 1996; accepted in revised form August 8, 1996. 


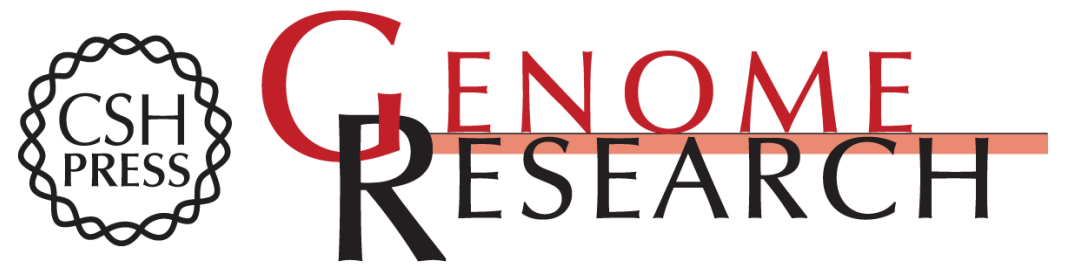

\section{An expanded CAG repeat sequence in spinocerebellar ataxia type 7.}

K Lindblad, M L Savontaus, G Stevanin, et al.

Genome Res. 1996 6: 965-971

Access the most recent version at doi:10.1101/gr.6.10.965

References This article cites 21 articles, 3 of which can be accessed free at:

http://genome.cshlp.org/content/6/10/965.full.html\#ref-list-1

\section{License}

Email Alerting Receive free email alerts when new articles cite this article - sign up in the box at the Service top right corner of the article or click here.

\section{Affordable, Accurate Sequencing.}

To subscribe to Genome Research go to: https://genome.cshlp.org/subscriptions 